\title{
PENGARUH MOTIVASI KERJA TERHADAP KINERJA KARYAWAN DI CV SURYA PRIMA SOLUSINDO SURABAYA
}

\author{
Wisnu Priambodo \& M. Taufiq \\ wisnu.priambodo@gmail.com \\ wisnupriambodo@unisla.com
}

\begin{abstract}
Employee performance can be seen from work processes or work results. A job always has steps (procedures) work, work procedures always lead to increased work results in accordance with the demands of work. The purpose of this research based on revelation according to Sedarmayanti (2011) reveals that: "Performance is a translation of performance which means the work of a worker, a management process or an organization as a whole, where the results of the work must be shown concretely and can be measured (compared with predetermined standards)". The population in this study is the effect of work motivation on employee performance at Surya Prima Solusindo CV prosperous. The sample taken is the sample extinct while according to Arikunto (2016) "Determination of taking If less than 100 is better taken all until the research is population research. The research findings show that it was found that the value was 0.030 which is a or equal to 0.05 so it can be concluded that $\mathrm{HO}$ is rejected and $\mathrm{Ha}$ is accepted which means that motivation has a significant influence on performance.
\end{abstract}

Keywords: work motivation, performance, employees

\section{PENDAHULUAN}

Pada Era global saat ini tantangan dalam dunia usaha semakin lama semakin bertambah, agar perusahaan bisa tetap eksis bertahan di dunia usaha makan perusahaan harus mampu bertahan dalam persaingan dunia usaha. Persaingan usaha kinerja antar satu supplier dan distributor terhadap penjualan barang dan jasa yang diminta oleh perusahaan pemesan. Pengusaha penyedia jasa dan barang tersebut memiliki berbagai macam masalah dan tantangan. Masalah yang sering kali di dapatkan dari segi motivasi kinerja, pendapatan, etos kerja karyawan. Hal tersebut sering kali memengaruhi hasil kinerja karyawan sehingga membuat pendapatan perusahaan menjadi lesu.

Sumber daya manusia merupakan salah satu aset terpenting bagi perusahaan, karena setiap kegiatan perusahaan tidak akan berjalan jika sumber daya perusahaan tidak terpenuhi.
Sumber daya manusia yang memiliki kualitas yang baik dari segi pendidikan, keterampilan, dan kemampuan kerja merupakan harapan setiap perusahaan. Salah satu faktor yang menjadikan kualitas sumber daya manusia baik adalah dari motivasi kerja sumber daya manusia tersebut. Motivasi kerja yang baik akan menjadikan kinerja yang baik pula sehingga mampu meningkatkan kualitas perusahaan dari segi sumber daya manusia.

Salah satu cara perusahaan meningkatkan kinerja perusahaan dengan cara meningkatkan motivasi. Menurut Wibowo (2010), motivasi merupakan dorongan terhadap serangkaian proses perilaku manusia pada pencapaian tujuan. Sedangkan elemen yang terkandung dalam motivasi meliputi unsur membangkitkan, mengarahkan, menjaga, menunjukkan intensitas, bersifat terus-menerus dan adanya tujuan. Menurut Aziz (2017) Kurang adanya motivasi kinerja menjadi- 
kan salah satu faktor negatif adalah menurunnya keinginan pegawai untuk mencapai prestasi kerja, kurangnya ketepatan waktu dalam menyelesaikan pekerjaan sehingga kurang menaati peraturan.

Kinerja karyawan merupakan indikator perusahaan dalam meningkatkan progres ke depannya. Menurut Abdullah (2014) kinerja merupakan gambaran mengenai tingkat pencapaian pelaksanaan suatu program kegiatan atau kebijakan dalam mewujudkan sasaran, tujuan, visi, dan misi dari organisasi yang dituangkan dalam strategi suatu organisasi. Dengan kata lain, kinerja karyawan merupakan wujud dari tanggung jawab pekerjaan dan tugas yang diberikan oleh pimpinan kepada bawahan dan cara menyelesaikan tugas tersebut dengan tepat waktu merupakan tanggung jawab karyawan itu sendiri.

Pada CV Surya Prima Solusindo merupakan salah satu perusahaan dengan dan perusahaan jasa yang menjual kebutuhan barang IT seperti halnya spare part printer, komputer dan CCTV. Adapun jenis usaha lainnya adalah service PC, printer, dan perawatan rutin komputer. Kebutuhan dengan adanya sumber daya manusia yang diharapkan dengan kemampuan karyawan tersebut dalam bidang IT merupakan kebutuhan di mana karyawan harus memiliki kemampuan mengerti produk komputer dan perlakuan terhadap beberapa hardware. Hal ini merupakan kewajiban bagi karyawan untuk menjadi bagian teknisi maupun dari logistik. Kinerja karyawan hanya sekadar menjalankan tugas tanpa ada keinginan melakukan inovasi. Hal ini dikarenakan kurangnya motivasi untuk berkembang dan memajukan perusahaan sehingga perkembangan perusahaan melamban atau hanya sekadar menjalankan usaha saja.

Tujuan dari penelitian yang dilakukan ini adalah untuk mendeskripsikan penerapan moti- vasi kerja, menganalisis pengaruh antara motivasi kerja terhadap kinerja karyawan CV Surya Prima Solusindo.

\section{KAJIAN PUSTAKA}

\section{Motivasi}

Motivasi merupakan hasil sejumlah proses yang bersifat internal atau eksternal bagi seorang individu yang menyebabkan timbulnya sikap antusias dalam melaksanakan suatu kegiatan yang timbul dari dalam dirinya sendiri. Menurut Hasibuan (2016) motivasi adalah pemberian daya penggerak yang menciptakan kegairahan seseorang agar mereka mau bekerja sama, bekerja efektif, dan terintegrasi dengan segala daya upayanya untuk mencapai kepuasan (Hasibuan, 2016).

Menurut Munandar (2011) menjelaskan tentang aspek-aspek motivasi kerja adalah sebagai berikut.

a. Adanya kedisiplinan dari karyawan

Sikap tingkah laku atau perbuatan pada karyawan untuk melakukan aktivitas-aktivitas kerja yang sesuai dengan pola-pola tertentu. Keputusan-keputusan dan norma-norma yang telah ditetapkan dan disetujui bersama baik tulis maupun lisan serta sanggup menerima sanksi bila melanggar tugas dan wewenang yang diberikan.

b. Imajinasi yang tinggi dan daya kombinasi

Membuat hasil kerja dan kombinasi ide-ide atau gambaran disusun secara lebih teliti atau inisiatif sendiri bukan ditiru dan bersifat konstruktif sehingga membentuk suatu hasil atau produk yang mendukung pada kualitas kerja yang lebih baik.

c. Kepercayaan diri

Perasaan yakin yang dimiliki karyawan terhadap kemampuan dirinya. Daya berpikir 
positif dalam menghadapi kenyataan yang terjadi serta bertanggung jawab atas keputusan yang dapat diambil sehingga dapat menyelesaikan masalahnya dengan tenang.

\section{Kinerja}

Kinerja karyawan atau performance merupakan gambaran mengenai tingkat pencapaian pelaksanaan suatu program kegiatan atau kebijakan dalam mewujudkan sasaran, tujuan visi dan misi organisasi yang dituangkan melalui perencanaan strategi suatu organisasi. Hasil kinerja karyawan sesuai tugas dan kemampuan karyawan itu sendiri.

Menurut Moeheriono (2010) kinerja karyawan atau definisi kinerja atau performance sebagai hasil kinerja yang dapat dicapai oleh seseorang atau kelompok orang dalam suatu organisasi baik secara kualitatif maupun secara kuantitatif sesuai dengan kewenangan, tugas, dan tanggung jawab masing-masing dalam upaya mencapai tujuan organisasi bersangkutan secara legal, tidak melanggar hukum dan sesuai dengan moral ataupun etika.

Menurut Edi Sutrisno (2016) kinerja adalah kesuksesan seseorang dalam melaksanakan tugas, hasil kerja yang dapat dicapai oleh seseorang atau sekelompok orang dalam organisasi sesuai wewenang dan tanggung jawab masing-masing atau tentang bagaimana seseorang diharapkan dapat berfungsi dan berperilaku sesuai tugas yang telah dibebankan kepadanya serta kuantitas, kualitas, dan waktu yang digunakan dalam menjalankan tugas.

\section{Tujuan Kinerja}

Menurut Veithzal Rivai (2011) tujuan kinerja adalah untuk memperbaiki dan meningkatkan kinerja organisasi melalui peningkatan kinerja SDM organisasi, tujuan penilaian kinerja karyawan, pada dasarnya meliputi:

1. meningkatkan etos kerja

2. meningkatkan motivasi kerja

3. untuk mengetahui tingkat kinerja

4. karyawan selama ini

5. untuk mendorong tanggung jawab dari karyawan

6. pemberian imbalan yang sesuai

7. untuk pembeda antar-pegawai yang satu dengan yang lainnya

8. pengembangan SDM

\section{Faktor Kinerja karyawan}

Menurut Anwar Prabu Mangkunegara (2010) menyatakan bahwa faktor yang memengaruhi kinerja sebagai berikut.

a) Faktor kemampuan

Secara psikologis kemampuan (ability) pegawai terdiri dari kemampuan potensi (IQ) dan kemampuan realita (pendidikan). Oleh karena itu, pegawai perlu ditempatkan pada pekerjaan yang sesuai dengan keahliannya.

b) Faktor motivasi

Motivasi terbentuk dari sikap (attitude) seorang pegawai dalam menghadapi situasi (situation) kerja. Motivasi merupakan kondisi yang menggerakkan diri pegawai terarah untuk mencapai tujuan kerja. Sikap mental merupakan kondisi mental yang mendorong seseorang untuk berusaha mencapai potensi kerja secara maksimal. David C. Mc Cleland (1997) seperti dikutip Mangkunegara (2010: 68) yang berpendapat bahwa "ada hubungan yang positif antara motif berprestasi dengan pencapaian kerja”. Motif berprestasi dengan pencapaian kerja. Motif berprestasi adalah suatu dorongan dalam diri seseorang untuk melakukan suatu kegiatan atau tugas dengan 


\begin{tabular}{|c|c|}
\hline Motivasi Keria & Kinerja \\
\hline \multirow{4}{*}{$\begin{array}{l}\text { 1. Rasa Aman } \\
\text { 2. Fisiologi } \\
\text { 3. Penghargaan } \\
\text { 4. Pengakuan } \\
\text { diri }\end{array}$} & 1. Keandalan \\
\hline & 2. Sikap \\
\hline & 3. Kualitas kerja \\
\hline & 4. Kuantitas kerja \\
\hline
\end{tabular}

Sumber Robbins (2012) dan Mangkunegaran (2011)

Gambar 1 Kerangka Konseptual Pengaruh Motivasi Kerja Terhadap Kinerja Karyawan di CV Surya Prima Solusindo
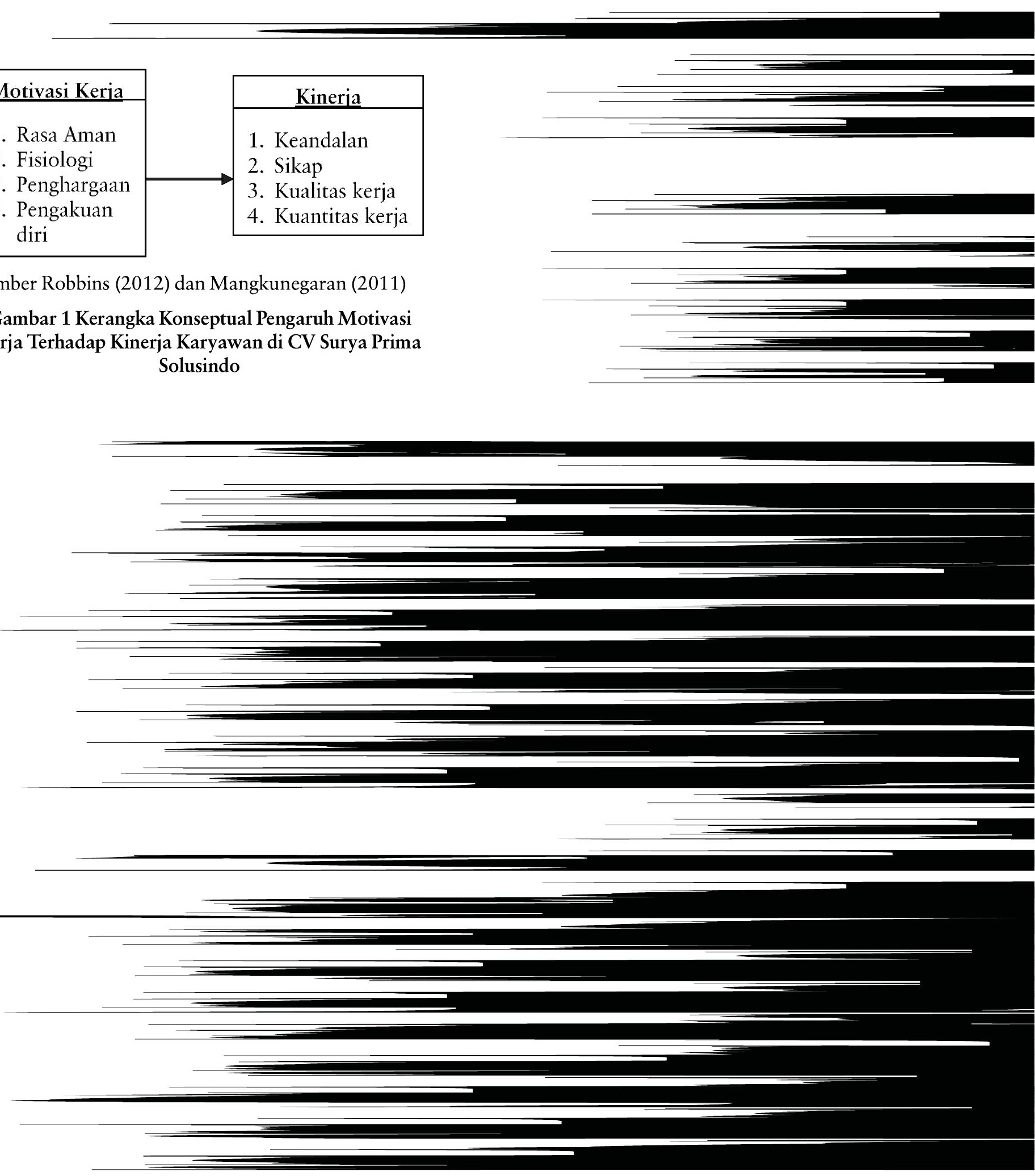


\section{c. Scoring}

Setelah diberikan kode angka pada lembar kuesioner maka selanjutnya diberikan skor dari semua pertanyaan. Kemudian dari hasil skoring dikategorikan menurut kriteria kategori menurut sugiono (2013).

\section{d. Tabulating}

Tabulasi adalah proses menempatkan data dalam bentuk tabel dengan cara membuat tabel yang berisikan data sesuai dengan kebutuhan analisis. Data hasil dari pengumpulan Kuesioner di-coding kemudian dimasukkan ke dalam tabel. Hasil pengolahan data dalam bentuk persentase kemudian diinterpretasikan dengan menggunakan skala kuantitatif sebagai berikut.

$$
\begin{array}{ll}
100 \% & =\text { seluruhnya } \\
76-99 \% & =\text { hampir seluruhnya } \\
51-75 \% & =\text { sebagian besar } \\
50 \% & =\text { setengah } \\
26-49 \% & =\text { hampir setengahnya } \\
1-25 \% & =\text { sebagian kecil } \\
0 \% & =\text { tidak satu pun }
\end{array}
$$

e. Entry data

Data yang sudah diberi kode kemudian dimasukkan ke dalam program komputer untuk diproses pengolahan datanya menggunakan komputer.

\section{f. Cleaning}

Cleaning merupakan kegiatan pengecekan kembali data yang dimasukkan, dilakukan bila terdapat kesalahan dalam memasukkan data yaitu dengan melihat distribusi frekuensi dari variabel-variabel yang diteliti.

\section{Analisis Data}

Data dianalisis dengan menggunakan uji korelasi Rank Spearman dengan kemaknaan $(\alpha=0,05)$ kemudian dianalisis dengan bantuan perhitungan komputer SPSS 17.0 for Windows. Dengan hasil uji, apabila nilai signifikansi $\mathrm{r}<\alpha$ (0.05) maka Ho ditolak dengan berarti ada hubungan kontrol diri dalam menggunakan media sosial dengan kejadian insomnia pada remaja di SMK Sejahtera Surabaya. Apabila signifikansi $\mathrm{r}>\alpha(0.05)$ maka Ho diterima dengan berarti tidak ada hubungan kontrol diri dalam menggunakan media sosial dengan kejadian insomnia pada remaja di SMK Sejahtera Surabaya.

\section{PEMBAHASAN}

\section{Data Penelitian}

a. Karakteristik responden berdasarkan jenis kelamin

Tabel 1 Distribusi Frekuensi Responden Berdasarkan Jenis Kelamin Karyawan

\begin{tabular}{lcc}
\hline Jenis Kelamin & Frekuensi & \% \\
\hline Perempuan & 9 & 35 \\
\hline Laki-laki & 15 & 65 \\
\hline Total & $\mathbf{2 3}$ & $\mathbf{1 0 0}$ \\
\hline
\end{tabular}

Sumber: Data Primer

b. Karakteristik responden berdasarkan data pendidikan responden

Tabel 2 Distribusi Frekuensi Responden Berdasarkan Data Pendidikan Responden

\begin{tabular}{lcc}
\hline \multicolumn{1}{c}{ Pendidikan } & Frekuensi & \% \\
\hline SMA/ SMK & 18 & 78 \\
\hline S1 & 4 & 17 \\
\hline S2 & 1 & 5 \\
\hline Total & 23 & 100,00 \\
\hline
\end{tabular}

Sumber: data Primer 


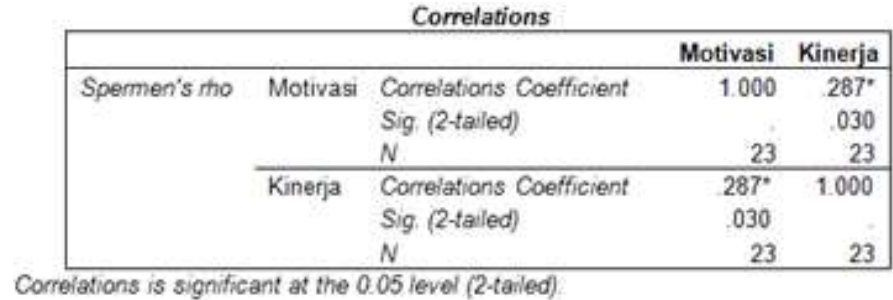

Berdasarkan uji korelasi yang didapatkan bahwa signifikan bernilai 0.030 yang mana $\alpha$ atau sama dengan 0.05 maka dapat disimpulkan bahwa $\mathrm{HO}$ ditolak dan Ha diterima yang artinya motivasi memiliki pengaruh secara signifikan terhadap kinerja.

\section{KESIMPULAN DAN SARAN}

Berdasarkan pembahasan hasil penelitian yang telah dilakukan tentang pengaruh motivasi kerja terhadap kinerja karyawan dengan mempertimbangkan maka dapat disimpulkan sebagai berikut.

1. Motivasi kerja berpengaruh signifikan terhadap kinerja karyawan sehingga apabila motivasi kerja yang diberikan semakin tinggi maka kinerja karyawan akan semakin tinggi.

2. Motivasi kerja salah satu cara perusahaan untuk meningkatkan kinerja karyawan sehingga memberikan dampak baik bagi usaha.

\section{DAFTAR RUJUKAN}

A.A. Anwar Prabu Mangkunegara. 2011. Manajemen Sumber Daya Manusia Perusahaan. Bandung: PT Remaja Rosdakarya.
Arikunto, S. 2016. Prosedur Penelitian Suatu Pendekatan Praktik. Jakarta: Rineka Cipta. Aziz, Umi Utaminingsih. 2017. Pengaruh Stres Kerja dan Motivasi Terhadap Kinerja Karyawan. Surakarta: Universitas Muhammadiyah Surakarta (Naskah Publikasi UMS).

Abdullah, M. 2014. Manajemen dan Evaluasi Kinerja Karyawan. Yogyakarta: Penerbit Aswaja Pressindo.

Edi Sutrisno. 2016. Manajemen Sumber Daya Manusia. Jakarta: Prenadamedia Group. Hasibuan, Malayu S.P. 2016. Manajemen Sumber Daya Manusia. Edisi Revisi. Jakarta: Penerbit PT Bumi Aksara.

Munandar, A.S. 2011. Psikologi Industri dan Organisasi. Jakarta: Universitas Indonesia (UI-Press).

Moeheriono. 2010. Pengukuran Kinerja Berbasis Kompetensi. Surabaya: Ghalia Indonesia.

Rivai, Veithzal. 2011. Manajemen Sumber Daya Manusia untuk Perusahaan: dari Teori ke Praktik. Jakarta: RajaGrafindo Persada.

Robbins, P. Stephen dan Timothy A. Judge. 2012. Perilaku Organisasi. Jakarta: Salemba Empat.

Sugiyono. 2013. Metode Penelitian Pendidikan Pendekatan Kuantitatif, Kualitatif, dan R\&DD. Bandung: Alfabeta.

Sedarmayanti. 2011. Sumber Daya Manusia dan Produktivitas Kerja. Bandung: CV Mandar Maju.

Wibowo. 2010. Manajemen Kinerja. Jakarta: Rajawali Press. 